\title{
Working
}

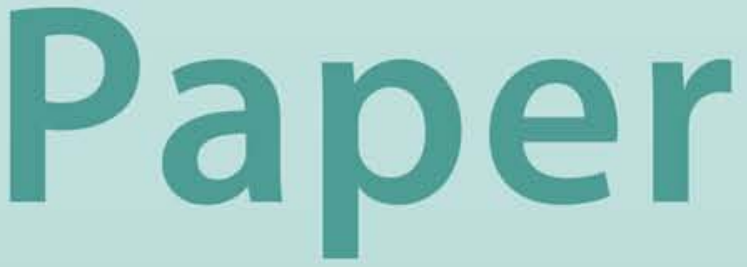




\section{Good, Bad or Ugly? \\ On The Effects of Fiscal Rules with \\ Creative Accounting}

Gian Maria Milesi-Ferretti 


\title{
IMF Working Paper
}

\author{
Research Department \\ Good, Bad or Ugly? \\ On The Effects of Fiscal Rules with Creative Accounting
}

\author{
Prepared by Gian Maria Milesi-Ferretti ${ }^{1}$ \\ Authorized for distribution by Eduardo Borensztein
}

October 2000

\begin{abstract}
The views expressed in this Working Paper are those of the author(s) and do not necessarily represent those of the IMF or IMF policy. Working Papers describe research in progress by the author(s) and are published to elicit comments and to further debate.
\end{abstract}

Do fiscal rules likely lead to fiscal adjustment, or do they encourage the use of "creative accounting'? This question is studied with a model in which fiscal rules are imposed on 'measured' fiscal variables, which can differ from 'true' variables because there is a margin for creative accounting. The probability of detecting creative accounting depends on its size and the transparency of the budget. The model studies the effects on fiscal policy of different rules, separating structural from cyclical effects, and examines how these effects depend on the underlying fiscal distortion and on the degree of transparency of the budget.

JEL Classification Numbers:E62, H61, H62

Keywords: Fiscal rules, creative accounting, budget transparency

Author’s E-Mail Address: gmilesiferretti@imf.org

\footnotetext{
${ }^{1}$ I am grateful to Alberto Alesina, Zaohui Chen, Tito Cordella, Pietro Garibaldi, Nissan Liviatan, Torsten Persson, Alessandro Prati, Jorge Roldós, and seminar participants at the IMF, the CEPR ESSIM conference in Vouliagmeni and the Political Economy of European Integration meeting in Berkeley for useful suggestions. I am responsible for all remaining cases of 'creative algebra.'
} 


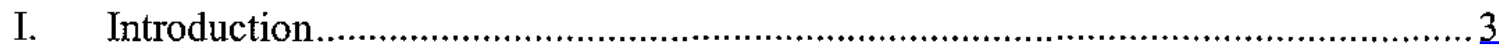

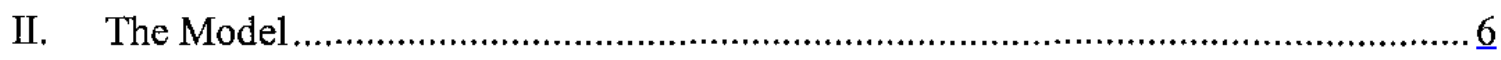

A. Deficit Rule and Creative Accounting ................................................

III. Budget Rules with Output Shocks ............................................................... 13

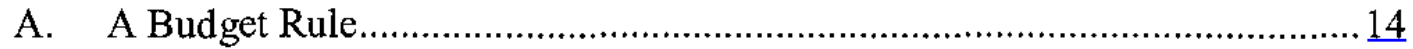

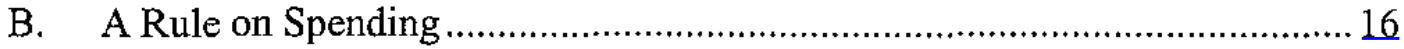

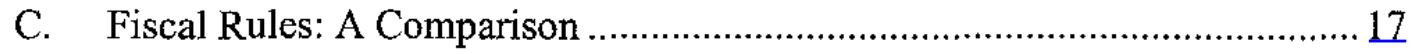

IV. Concluding Remarks.............................................................................. 18

Figure 1. Fiscal Rules and "Cyclical" Losses ................................................... 19

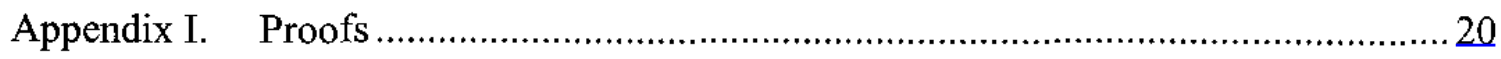

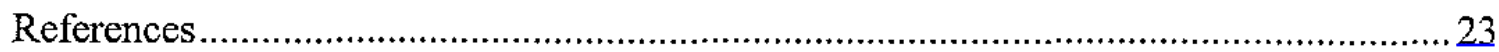




\section{INTRODUCTION}

Fiscal rules are at the center of public attention and of the policy debate in several countries. In the United States, the proposal for a balanced budget amendment failed to win Senate approval by a single vote. In countries belonging to the European Union, respect of the socalled Maastricht criteria on fiscal deficits and government debt has been a central issue on the run up to the single currency. The same countries have devised a 'stability pact' to ensure fiscally responsible behavior after monetary union takes place. Numerical fiscal targets play an important role in the context of conditional lending programs by the International Monetary Fund.

But what arguments support legal or regulatory restraints on the ability of governments to choose their levels of taxation and spending? And why have they attracted so much attention? An explanation probably has to rely on the emergence of large fiscal imbalances in a number of OECD and developing countries during the 1970s and 1980s, leading to rapid accumulation of public debt. This led to concerns that political forces, together with the procedures whereby budgets are made and implemented, have an inherent bias towards deficits. The imposition of numerical rules on budget deficits is viewed as one possible way to reduce or eliminate this bias. However, such rules can have important shortcomings. Rules that are not contingent on the macroeconomic cycle can force governments to tighten fiscal policy during cyclical downturns, thus exacerbating macroeconomic fluctuations--a concern often expressed in European Union countries. Furthermore, the imposition of numerical rules may encourage the use of dubious accounting practices, thereby reducing the degree of transparency in the government budget. Concerns that fiscal rules can lead to less transparent budgets have gained strength with the use of 'creative accounting' by a number of European countries in order to facilitate meeting the ceiling on the budget deficit established in the Maastricht treaty.

This paper provides a simple framework designed to address these questions. Its title paraphrases three positions that can be taken with respect to the effects of rules. Rules can lead to good outcomes, by inducing profligate governments to engage in virtuous fiscal behavior. Or they can lead to bad outcomes, as they hinder the use of counter cyclical fiscal policy and hamper the operation of automatic fiscal stabilizers. Or, finally, they can lead to ugly outcomes: namely, a lot of window dressing and creative accounting, but little overall effect on fiscal policy.

The model is based on three simple observations. The first is that the rationale for a budget rule has to be based on the existence of a distortion, such as a deficit bias or an excess spending bias, that causes discretionary fiscal policy to deviate from a socially desirable benchmark. Otherwise, there is clearly no benefit from imposing constraints on fiscal policy conduct. The second observation is that rules are imposed on 'measured' fiscal aggregates (deficit, public debt, or government spending), which can differ from the economically meaningful ones (which matter for government solvency) because there is a margin in the budget for 'window dressing.' Numerous studies document pitfalls and shortcomings of traditional indicators of fiscal policy (see, for example, Blejer and Cheasty (1991) and the 
discussion of budget transparency in Kopits and Craig (1998)). The third observation is that window-dressing measures may imply costs for the government: for example, they may be deemed inadmissible for the attainment of the required budget balance, they can imply reputation costs for the government, or, more directly, cause distortions and hence economic costs. The model focuses primarily on costs of the first type, and assumes that such costs are likely to depend on the ability of the public to monitor the government's budgetary actions (itself a function of the degree of transparency of the budget) and on the size of the windowdressing measures. Based on these observations, the model studies the effects of different types of budget rules on fiscal policy, separating structural from cyclical effects, and examines how these effects depend on the underlying fiscal distortion and on the degree of transparency of the budget.

It is clearly important to establish at the outset what creative accounting means in the context of this paper. A broad definition is the following: a measure implying an improvement in the fiscal balance is considered to be creative accounting if it does not imply an improvement in the intertemporal budgetary position of the government sector at large (an increase in the government's net worth). ${ }^{2}$ The literature provides several examples. Easterly (1999) argues that fiscal adjustment in a number of developing countries with World Bank and IMF programs relied heavily on a decumulation of government assets (mainly through reductions in public investment and in expenditure on operations and maintenance), implying that the reduction in government liabilities did not necessarily correspond to an increase in the government' net worth. Bunch (1991) presents evidence that US states with constitutional debt limits use public authorities to circumvent borrowing restrictions, and Kiewiet and Szakaly (1996) find that constitutional limitations pertaining only to guaranteed state debt do not meaningfully affect the total amount of debt issued by state and local public authorities.

A number of well-known examples also occurred in the run-up to EMU:

(i) In France, the budget deficit in 1997 was reduced by around 0.5 percent of GDP thanks to a one-time payment from France Télécom, a public enterprise, to compensate the state for taking on its pension liabilities. The payment was structured as a capital receipt, therefore counting for deficit reduction, rather than an asset transaction, which would have reduced the debt, but not the deficit. This was possible because public enterprises are not part of 'general government' in the sense of the Maastricht treaty.

(ii) In Greece, capital transfers to public enterprises were recorded as 'equity increases,' and thus excluded from the calculation of the budget deficit (with approval from Eurostat). This

\footnotetext{
${ }^{2}$ There are also instances in which creative accounting measures can actually imply a worsening of the government's intertemporal budget position, as would be the case when, for example, a cut in transfers to lower levels of government forces them to borrow at rates that are higher than those at which the government can borrow.
} 
measure, together with a reduction in interest payments due to the issuance of zero-coupon bonds, accounted for a reduction the 1997 budget deficit of over 1 percent of GDP.

(iii) In Italy, two sentences of the Constitutional Court forced the government to pay back pension outlays for an approximate amount of 0.2 percent of GDP. These payments, financed through bond issuance, took place between 1997 and 2000, but were retroactively imputed to the budgets of the years the liabilities were incurred in (1993-95), leaving the budget deficits for the years 1997-2000 unaffected. ${ }^{3}$ Also the accounting of capitalized interest on postal savings certificates was shifted from an accrual to a cash basis. As a result, interest payments are now recorded only when they fall due, analogously to zero-coupon bonds, thus reducing the deficit by 0.3 percent of GDP. Finally, debts of the railway company were recognized as government debt. This implies that the amortization of capital on this debt, which was previously recorded as a transfer to a state enterprise, is now treated as the repayment of a government liability and as such it does not affect the budget deficit. ${ }^{4}$

The rationale for a fiscal rule relies on the existence of some underlying distortion that causes discretionary fiscal policy to diverge from society's preferences. There is a vast political economy literature that provides possible explanations as to why governments may systematically deviate from 'sound' principles of fiscal policy, by focusing on how economic, institutional, political and distributional factors interact in shaping policy decisions (see Alesina and Perotti (1995) for a survey). This literature focuses mainly on how a bias towards excessive deficits or excessive government spending may arise, rather than on the effects of fiscal rules per se. Theoretical studies of the effects of budget rules have taken two approaches. The first has been to examine the impact of rules in the absence of any underlying distortion in the conduct of fiscal policy. In this context, Schmitt-Grohe and Uribe (1997) show that in a neoclassical growth model a balanced budget rule can make expectations of higher tax rates self-fulfilling if the fiscal authority relies on changes in labor income tax rates to balance the budget. This happens because the expectation of high tax rates lowers labor supply and therefore output, forcing taxes to be raised to balance the budget. Chari and Kehoe (1997) argue that fiscal constraints in a monetary union can be desirable if no monetary policy commitment is possible. The reason is that national fiscal authorities take into account the incentive of the central bank to partially monetize debt, but do not internalize the costs of induced inflation on other member states. The second approach studies budget rules in the presence of an underlying distortion in the discretionary conduct of fiscal policy (a necessary, but not sufficient, condition for a fiscal rule to be desirable). Corsetti and Roubini (1997) highlight the trade-off between deficit bias and margin for stabilization inherent in the choice of fiscal rules, and emphasize how the intensity of the

${ }^{3}$ However, in the calculation of the stock of debt the payments have been accounted for in the years in which the bonds are actually issued (1997-2000).

4 The so-called "tax for Europe," a tax surcharge imposed for the fiscal year 1997 that was partly reimbursed in 1999, is arguably (in part) another example of creative accounting. 
fiscal policy bias can be related to the degree of capital market integration. ${ }^{5}$ Beetsma and Uhlig (1999) study the rationale for a 'stability pact' limiting fiscal imbalances in a monetary union, using a model in which politicians have a deficit bias and there is an incentive to erode debt through unexpected inflation. Dur et al. (1997) show that a fiscal rule, imposed to address a deficit bias problem, may have undesirable effects on the composition of public spending, leading to a suboptimally low level of public investment.

All these papers assume that a fiscal rule is fully binding. This paper instead assumes, more realistically and in line with existing empirical evidence, that the government has a margin of flexibility in the implementation of a fiscal rule; it investigates how this margin affects the conduct of fiscal policy when rules are imposed and draws implications for the usefulness of rules. The model is presented in Section II. Section III considers how the presence of shocks affecting expenditure and revenues impacts on the choice and desirability of fiscal rules. In particular, it compares a fixed deficit rule, which targets the fiscal distortion but hampers the ability to respond to budget shocks, with a spending rule, that targets only part of the fiscal distortion but allows taxes to respond to shocks. Section IV concludes.

\section{THE MODEL}

The two-period, reduced-form model borrows from von Hagen and Harden (1996). In summary, the government chooses taxes and government spending so as to minimize a convex loss function which is increasing in the level of taxation and in deviations of spending from its desired level. The distortion in the conduct of fiscal policy is introduced by assuming that there is a positive probability that the government discounts the future more heavily than 'society.' The assumption that a fiscal rule is imposed on the 'measured' fiscal deficit, which can differ from the actual (i.e., economically meaningful) one, generates a margin for creative accounting. If the public detects that the rule is met de iure but not de facto the government has to pay the penalty for not meeting the rule, thus implying a disincentive to using creative accounting. The role of budget transparency is introduced by assuming that the probability of detection of creative accounting is increasing in the degree of transparency.

Formally, the government chooses the path of taxes $\left(T_{1}, T_{2}\right)$ and government spending $\left(G_{1}\right.$, $G_{2}$ ) so as to minimize the following quadratic loss function:

\footnotetext{
${ }^{5}$ The nature of the trade-off between flexibility and deficit bias is apparent in some of the empirical work on the link between statutory fiscal restraints and budgetary outcomes within US States. ACIR (1987), von Hagen (1991) and Bohn and Inman (1996), among others, find that states with such restraints run smaller budget deficits, while Bayoumi and Eichengreen (1995) find that the cyclical responsiveness of state budgets is significantly reduced by the presence of fiscal restraints. See also Poterba $(1994,1995)$.
} 


$$
\begin{aligned}
& L^{g}=\frac{\alpha}{2}\left(G_{1}-G^{*}\right)^{2}+\frac{1}{2} T_{1}^{2}+\beta^{*}\left[\frac{\alpha}{2}\left(G_{2}-G^{*}\right)^{2}+\frac{1}{2} T_{2}^{2}\right] \\
& \alpha>0,0<\beta^{*} \leq 1
\end{aligned}
$$

where $G^{*}$ is the desired level of spending (when taxes are not distortionary). This loss function could easily be derived from a simple endowment model in which consumers' utility is linear in private consumption and quadratic in government spending. The choice of fiscal policy variables must obey the intertemporal budget constraint

$$
G_{1}-T_{1}+\frac{1}{R}\left(G_{2}-T_{2}\right)=0
$$

where $R$ is the interest factor $(1+r)$, taken as given. The preferences of private agents are also given by (1), with $\beta^{*}=1 / R$.

The government type is picked by nature from a binomial distribution and is unobservable by private agents. The two possible government types differ only in their discount rate: a social planner has preferences that reflect those of private agents $\left(\beta^{*} R=1\right)$, while a myopic government discounts the future at a rate that is higher than the rate of interest; that is, $\beta^{*}=\beta$ $<1 / R$. For example, this higher discount rate can reflect the possibility that the current policy maker will not be in power in the second period. The probability that the government is myopic is $q<1$.

The policies chosen by a myopic government are indicated with the superscript $m$, those chosen by a social planner with the superscript $p$, those undertaken under discretion with the superscript $d$ and those undertaken under a rule with the superscript $r$. Given the assumption that the optimal level of spending $G^{*}$ is the same in both periods, the optimal policy from the point of view of the public and of the social planner is clearly a balanced budget:

$$
G_{1}^{p d}=T_{1}^{p d}=\frac{\alpha}{1+\alpha} G^{*}
$$

The higher discount rate of the myopic government implies that it will run a budget deficit in the first period, given by

$$
G_{1}^{m d}-T_{1}^{m d}=D_{1}^{m d}=\frac{1-\beta R}{1+\beta R^{2}} G^{*}
$$

The deficit bias is clearly a function of the difference between the discount rate and the rate of interest. 


\section{A. Deficit Rule and Creative Accounting}

The fact that the government can be myopic implies that, on average, the economy will have a budget deficit, and there is therefore a rationale for imposing a fiscal rule. We shall consider two cases: the first in which the rule is chosen by the public, and the second in which the rule is chosen by an outside agent (such as a super-national authority). The basic assumptions of the model are the following:

Assumption 1a: A rule specifies that the budget deficit cannot exceed the level $D^{*}$. Violation of the rule implies a cost for the government equal to $K$.

We later consider the case in which the "punishment" for the detection of a violation of the rule is borne by the public as well, as would be the case, for example, with a financial penalty (Beetsma and Uhlig (1999)) or with exclusion of the country from a common currency. $D^{*}$ must clearly be smaller than the 'unconstrained' deficit of the myopic government $D^{\text {md }}$ for the rule to be binding.

Assumption 2: The fiscal rule is imposed on the 'measured' fiscal position $\Delta$, which can differ from the actual one $(D)$ because the government has a margin for creative accounting.

Assumption 3: The public cannot observe the actual value of taxes and spending at the end of period 1 .

Assumption 4: Creative accounting can be detected by the public with probability $p$, which is increasing in the degree of transparency of the budget $\gamma$ ' and in the size of creative accounting $D_{1}-\Delta$ :

$$
p=\gamma^{\prime}\left(D_{I}-\Delta\right)^{2} \quad p \leq 1
$$

If creative accounting is detected, the government bears the cost $K$ of not meeting the rule.

Assumption 3 is clearly necessary to introduce ex-post uncertainty about the conduct of fiscal policy. Assumption 4 simply states that the government incurs some risks in meeting the rule with creative accounting: if budgetary tricks come to light (with probability $p$ ) the penalty for not meeting the rule is paid. ${ }^{6}$ The parameter $\gamma^{\prime}$ proxies how difficult it is for the public to 'pierce the veil' of budgetary accounts and infer the true fiscal stance, and is henceforth

\footnotetext{
${ }^{6}$ In practice, some creative accounting measures can be "disallowed" by the enforcer of the rule. For example, Eurostat did not allow to count as deficit reduction the use of the proceeds from taxation of profits resulting from a "gold sale" of the Ufficio Italiano Cambi, a public body related to the Bank of Italy, to the Bank of Italy itself (total amount: 3 trillion lire). Nevertheless, Italy's deficit remained below 3 percent.
} 
referred to as the degree of transparency of the budget. ${ }^{7}$ This is taken to be a structural feature of the economy, which cannot be altered by the government. ${ }^{8}$ Clearly if the government meets the rule de facto $\left(D \leq D^{*}\right)$, it will choose to do no creative accounting. Assumption 4 implies that the government will always choose to meet the rule, at least de iure, by doing creative accounting, because it will pay the cost $K$ with a probability which is below unity. Alternatively, we could assume either that policymakers that are caught using accounting tricks bear some other cost unrelated to $K$ (for example, the Finance Minister loses his/her job or the government is kicked out of office), or that creative accounting measures impose distortionary costs on the economy. In both these cases, the government would face a meaningful choice between meeting the rule only de iure and choosing its discretionary policy without doing any creative accounting. As shown below, it is easy to reconcile the model's formulation with either alternative interpretation. Note also that in the setup of the model there is no scope for signaling, because the government is punished or rewarded with re-election if its preferences become known. ${ }^{9}$ The government's loss function, conditional on the measured deficit meeting the budget rule, is therefore amended as follows:

$$
L^{g}=\frac{\alpha}{2}\left(G_{1}-G^{*}\right)^{2}+\frac{1}{2} T_{1}^{2}+I p K+\beta\left[\frac{\alpha}{2}\left(G_{2}-G^{*}\right)^{2}+\frac{1}{2} T_{2}^{2}\right]
$$

where the indicator function $I=1$ when $D_{1}>D^{*}$ and 0 otherwise. Note that (6) is consistent with the existence of additional 'reputation' costs for the government if the rule is violated, as long as these costs take a quadratic form as well. If instead creative accounting induces distortions that are costly for the economy, it is necessary to amend the private agents' loss function as well: this is done further below.

What would be the behavior of a myopic government? From assumptions 1a-4 and equation (6) it follows immediately that the government will set $\Delta=D^{*}$. Since by assumption $D^{*}$ is smaller than the deficit the government would choose in the absence of a rule, there would be no reason to 'overshoot' $D^{*}$. ${ }^{10}$ The actual deficit will be determined by the choice of taxes

\footnotetext{
${ }^{7}$ Note that under the optimal rule some creative accounting always takes place, but the penalty can only be imposed if creative accounting is detected.

${ }^{8}$ Von Hagen and Harden (1994) discuss the difference in the degree of transparency of the budget in EU countries, and Alesina et al. (1996) in Latin American countries. Alesina and Cukierman (1990) show that the government could rationally choose 'ambiguous' procedures in order to make it more difficult for voters to infer its true type.

${ }^{9}$ See Rogoff and Sibert (1988) and Rogoff (1990) for models with signaling through fiscal policy.

${ }^{10}$ Note that an incentive to overshoot the target may arise if we allowed some scope for signaling, for example, by assuming that the public is more likely to re-elect a "social planner."
} 
and government spending to minimize (6), with $\Delta=D^{*}$, subject to the budget constraint (2). Inspection of (6), taking into account (5), shows that this setup is identical to one where the fiscal rule has an 'escape clause,' and the cost of deviating from the rule is proportional to the degree of transparency and increasing in the size of the deviation (see Obstfeld (1997) for model with exchange rate escape clauses). The optimal deficit will then be given by:

$$
D^{m r}=\frac{\alpha(1-\beta R) G^{*}+\gamma(1+\alpha) D^{*}}{\alpha\left(1+\beta R^{2}\right)+\gamma(1+\alpha)}
$$

where $\gamma=\gamma^{\prime} K$. The implications of $(7)$ are quite straightforward: when faced with a budget rule that it is costly to violate, the government will do some fiscal adjustment and some 'window dressing' in order to meet the rule. We are now able to state the first result.

Proposition 1: For a given cost of violating the rule, the balance between fiscal adjustment induced by the rule and 'window dressing' is determined by the degree of transparency of the budget $\gamma^{\prime}$.

Proof The fraction of total fiscal adjustment that reflects a change in the actual deficit is given by $\left(\left(D_{1}^{m d}-D_{1}^{m r}\right) /\left(D_{1}^{m d}-D^{*}\right)\right.$. This yields

$$
\frac{\gamma(1+\alpha)}{\alpha\left(1+\beta R^{2}\right)+\gamma(1+\alpha)}
$$

which is increasing in the degree of budget transparency $\gamma^{\prime}$.

As budget transparency increases, the amount of actual adjustment increases and the amount of creative accounting correspondingly decreases, because the rule becomes, in effect, more binding.

When the government is a social planner, its optimal policy is very simple. If the rule does not require a budget surplus, the budget will be balanced. If the rule requires a surplus, a social planner will also resort to creative accounting so as to meet the rule. But what is the optimal fiscal rule from society's point of view? In the absence of a margin for creative accounting, a balanced-budget rule would be optimal. Such a rule would be binding only for a myopic government, and the resulting policy choice would be the one preferred by private agents. In the presence of a margin for creative accounting, however, a balanced budget rule is not optimal anymore, because it will give rise, on average, to a fiscal deficit. When creative accounting imposes no costs on the public, the optimal fiscal rule will be 'tighter' than the desired fiscal outcome, because there is a positive probability that the government is myopic and would therefore resort to cosmetic changes in the deficit, in addition to fiscal adjustment: 
Proposition 2a: Under assumptions 1a-4, the optimal rule requires a budget surplus. The size of the surplus is positively related to the size of the deficit bias and to the probability the government is myopic, and negatively related to the degree of transparency.

Proof: See Appendix.

Proposition (2a) states that the optimal rule will 'overshoot' the desired fiscal balance. If the probability that the government is a social planner increases, there is less need for overshooting. The same happens if the budget is more transparent, since the rule is more binding (creative accounting is easier to detect). Of course, when the rule requires a budget surplus a social planner would indeed run a surplus and do some creative accounting. However, the cost of this deviation from a balanced budget is compensated by the reduction in the deficit bias for the myopic government. Note that, in expected value terms, the optimal rule described in Proposition 2 a implies an actual budget surplus, because of the risk aversion of private agents implicit in the concave utility function (see the Appendix for details). We turn now to the case in which creative accounting imposes costs on the public as well:

Assumption 1b: Creative accounting, if detected, imposes costs on both the government and the public.

This could represent the case of an external enforcer of the rule: if a country does not meet the fiscal rule, it has to pay a lump-sum financial penalty or bear some other form of cost (such as the exclusion from monetary union, or the interruption of a program of external financial assistance). We choose a simple specification of the way in which these costs enter the private agents' loss function:

$$
L^{p}=E\left(\frac{\alpha}{2}\left(G_{1}-G^{*}\right)^{2}+\frac{1}{2} T_{1}^{2}+\frac{m \gamma}{2}\left(D_{1}-D^{*}\right)^{2}+\frac{1}{R}\left[\frac{\alpha}{2}\left(G_{2}-G^{*}\right)^{2}+\frac{1}{2} T_{2}^{2}\right]\right)
$$

where we replaced $\Delta$ with $D^{*}$. The parameter $m$ measures the percentage of the cost $K$ borne by private agents. Alternatively, we could think that private agents and the government bear the same cost of violating the rule, and that $m$ captures the fraction of such costs internalized by an external enforcer. ${ }^{11}$ To roughly incorporate in the model the costs induced on other countries (say, on those enforcing the rule) by fiscal policy spillovers (for example in the form of higher interest rates, an argument frequently mentioned in justification of the Maastricht criteria), the enforcer's loss function can easily be amended by substituting the term in $m$ with a term capturing deviations of domestic fiscal policy from its optimal level (in this case a balanced budget).

${ }^{11}$ It is possible to reconcile this formulation with the case in which these costs are interpreted as distortions imposed by creative accounting. Assume that these distortionary costs take a quadratic form as well (with weight $k$ in the loss function) and let $\gamma^{*}=k+\gamma$. In that case the loss function would feature the parameter $\gamma^{*}$ (instead of $\gamma$ ) and the parameter $m$ would be equal to $k / \gamma^{*}$. 
If the rule is set by an external enforcer that maximizes private agents' utility without internalizing the costs of violating the rule, results would be exactly analogous to those of Proposition 2a. If instead the rule is set taking into account the costs imposed on private agents by a failure to fulfill it, $D^{*}$ would be chosen so as to minimize (9), subject to $\left(G_{1}, G_{2}\right.$, $T_{1}, T_{2}$ ) being chosen optimally by the government:

Proposition 2b: Under assumptions $1 b-4$, and as long as $m<(1+R) /\left(1+\beta R^{2}\right)$, the optimal rule still requires a budget surplus, albeit smaller than under assumption la (Proposition 1). The surplus is increasing in the size of the deficit bias and in the probability that the government is myopic, and decreasing in $m$ and in the degree of transparency.

Proof: See the Appendix.

Proposition $2 \mathrm{~b}$ states that the result regarding 'overshooting' of the budget rule holds even when creative accounting imposes costs on society at large, as long as these costs are not significantly greater than those imposed on the government. Note that, when $m=1$, the optimal rule implies, in expected value terms, a budget deficit (see Appendix). Even though the public (and/or the external enforcer) would like a balanced budget, a tighter rule would encourage creative accounting and a higher risk of violation, with implied costs that are increasing in $m$. Clearly, a higher degree of transparency reduces the incentive to use creative accounting and therefore reduces the expected deficit. Note finally that if the budget rule is set by an external enforcer, who does not fully internalize the penalty $K$, it would be considered too tight by domestic residents, who have to pay the full penalty if the creative accounting is detected.

Even if derived from a very stylized model, these results can provide some interesting insights concerning the debate over the Maastricht criteria as well as the debate over the role of transparency in the context of conditional lending by international organizations. For example, the model provides a simple justification for imposing a stricter fiscal rule on countries with less transparent budgets and a history of fiscal profligacy (a high $q$ or a high deficit bias). Conversely, it suggests that adoption of more transparent budgets may rationally lead to less stringent conditionality requirements in lending by international organizations. With regard to the Maastricht criteria, even though the deficit ceilings were nominally the same for each country, the (implicit) constraint on the budget deficit faced by the Italian government (but not by the French or German governments) may arguably have been tighter than 3 percent, because of Italy's history of fiscal profligacy. This would explain the fact that Italy's 1997 deficit was below the ceiling even in the face of a cyclical downturn. ${ }^{12}$

${ }^{12}$ An alternative (and possibly complementary) explanation is that Italy's government wanted to 'signal its type' by overshooting the deficit rule. The model can also explain why the public favors a less restrictive rule, when it has to bear the cost of violating it, with respect to an external enforcer. 


\section{BUDGET RULES WITH OUTPUT SHOCKS}

In the simple model examined so far, there is no stabilization role for fiscal policy; therefore, given the deficit bias, a budget rule is clearly optimal. However, a numerical rule can hamper the flexibility of fiscal policy to respond to stochastic shocks. To address this question, following Corsetti and Roubini (1997), we now assume that the actual deficit in period 1 has a stochastic component $\varepsilon$. This component can be interpreted as reflecting the operation of "automatic stabilizers" in the budget that respond to the business cycle, for given tax and expenditure decisions. ${ }^{13}$ The underlying output shock is assumed to be observable by the government before tax and expenditure decisions are taken, but not when the budget rule is determined. For simplicity, it is also assumed that no stochastic disturbances occur in period 2. The government's intertemporal budget constraint thus becomes:

$$
G_{1}-T_{1}-\varepsilon+\frac{1}{R}\left(G_{2}-T_{2}\right)=0 \quad \varepsilon: U(a, a)
$$

where for simplicity we assume that $a$ is sufficiently small so that the realization of the shock is never large enough to fully offset the deficit bias. ${ }^{14}$ Suppose, for example, that the shock is positive, and that it implies lower public expenditure (in the amount $\delta \varepsilon$ ) and higher tax revenue (in the amount $(1-\delta) \varepsilon$ ). The implicit assumption on the expenditure side is that the desired level of expenditure $G^{*}$ changes by $\delta \varepsilon$ as well (if output is high and unemployment benefits fall, so does the optimal level of spending). On the tax side, $T$ should be interpreted as the tax rate, rather than tax revenue-higher tax revenue when output is high does not imply more tax distortions. Therefore the loss function remains unchanged, except for the fact that the (actual) deficit now includes the term $\varepsilon$.

We first determine what would be the budget response to the shock most desired by private agents, and compare it with the response the myopic government would choose in the absence of a rule. We then examine the effects of imposing a rule on the ability of the government to react to the shock. Throughout this section we focus mainly on the cyclical part of the budget, which has two components: the actual shock plus the policy response to it.

\footnotetext{
${ }^{13}$ Corsetti and Roubini (1997) present a model in which the deficit bias is generated by a disagreement between parties over future spending priorities. Given electoral uncertainty, this implies that the government discounts future spending more than private agents. On the tax side, however, there is no difference in the rate of discount, and there is therefore an incentive to smooth taxes. Overall, this can give rise to a deficit bias.

${ }^{14}$ If this assumption is not satisfied, the qualitative features of the problem remain unchanged but the algebra is more complex, because of the non-linearity in the government's expected policy choice with respect to the rule.
} 
The analysis of the structural part of the budget is analogous to the one in the previous section.

The public would now like to achieve some smoothing of the shock between the two periods. The desired budget deficit is given by:

$$
D^{p d}=-\frac{\varepsilon}{1+R}
$$

A positive shock would hence lead to a budget surplus and vice versa. The 'discretionary" deficit choice of a myopic government is obtained by minimizing (1) subject to (9):

$$
D^{m d}=\frac{1-\beta R}{1+\beta R^{2}} G^{*}-\frac{1}{1+\beta R^{2}} \varepsilon
$$

An interesting result emerges when we compare (11) with (12). Namely, a myopic government's budget responds 'too much' to the shock with respect to what is optimal; because of the government's higher discount rate, the response of fiscal policy to the shock does not achieve sufficient "smoothing.'

\section{A. A Budget Rule}

Analogously to the previous section, consider now the case in which a fiscal rule is imposed on the first-period budget balance. Throughout this section we assume that this rule is not state-contingent, in line with the way fiscal rules are typically designed in practice (as, for example, the Maastricht admission criteria and the stability pact). The government chooses spending, taxes and 'window-dressing' so as to minimize the loss function (6), subject now to the budget constraint (10). Note in particular that $D$ is now equal to $G_{1}-T_{1}-\varepsilon$. The Appendix reports the 'structural' and 'cyclical' components of the chosen levels of taxes and spending. The deficit chosen by a myopic government is given by

$$
G_{1}^{m r}-T_{1}^{m r}-\varepsilon=D^{m r}=\frac{\alpha(1-\beta R) G^{*}+\gamma(1+\alpha) D^{*}-\alpha \varepsilon}{\alpha\left(1+\beta R^{2}\right)+\gamma(1+\alpha)}
$$

The 'structural' part of the budget deficit is clearly the same as in (7), and the same goes for the levels of spending and taxation. The rule implies that the budget deficit can change by less in response to cyclical disturbances with respect to the case in which there is no rule. Note, however, that this response is not entirely prevented, because of the margin for creative accounting.

According to conventional wisdom, numerical rules on the budget deficit impose costs because they hinder a cyclical response to the budget. Does this imply that, from the point of view of cyclical 'smoothing,' less transparency implies a more desirable cyclical response of the budget? This is not necessarily the case, as the following proposition clarifies. 
Proposition 3: At low levels of transparency, an increase in transparency implies a more desirable cyclical response of the budget to shocks when the government is myopic. At high levels of transparency, an increase in transparency implies a less desirable response of the budget to shocks.

Proof: Compare the cyclical components of (11), (12) and (13).

The budget response to the shock is decreasing in $\gamma$, the degree of transparency of the budget, but in the absence of a rule the budget would respond 'too much' to the shock (compare (11) with (12) above). Therefore, at low levels of $\gamma$, more transparency implies a response of the budget to shocks which is closer to agents' preferences. This implies that, at low levels of transparency, a rule can moderate a deficit bias, and also ensure a more appropriate response to shocks. As the degree of transparency rises and creative accounting becomes more costly, the margins for smoothing are eroded. In more general terms, Proposition 3 simply states that if fiscal policy conduct is subject to a bias there is no reason to presume that the government would choose an 'optimal' response to cyclical shocks. ${ }^{15}$

Note that the importance of the result of Proposition 3 depends on the likelihood that the government is indeed myopic. Since the discretionary deficit choice of a social planner would coincide with the choice of the public, a binding budget rule necessarily implies a less desirable response of the budget to shocks (compare (11) with (13), setting $\beta=1 / R$ ). While it is still true that at low levels of $\gamma$ an increase in transparency raises welfare (in expected value terms, the above-mentioned negative effect would be offset by the more desirable response obtained in the case the government is myopic) the intensity of the effect and the range of values of $\gamma$ over which this occurs depend on the value of $q$. This result is simply a reflection of the fact that as $q$ decreases the logic for the imposition of a budget rule is weakened, since discretionary fiscal policy gets closer and closer to the one desired by private agents.

In order to improve the responsiveness of the budget to cyclical shocks, a rule could establish that the budget has to be balanced over a longer period--for example, over the economic cycle--but not year by year. In the context of our analysis, this rule would require the extension of the model to more than two periods, because the intertemporal budget constraint requires a balanced budget on average over two periods. A rule specifying a balanced budget over two periods allows a better response to economic shocks with respect to a period-byperiod rule. However, the existence of a deficit bias implies that the government will still manage the structural part of the budget in a sub-optimal way, by running a budget deficit in

\footnotetext{
${ }^{15}$ A more extreme example of this point can be found in Tornell and Lane (1998); the authors show in the presence of a 'common pool' problem in fiscal policy conduct a 'voracity' effect can induce spending to rise more than proportionately following of a temporary positive shock. Clearly the 'cyclical advantage' provided by lack of transparency depends on the fact that the rule is not state contingent.
} 
the first period. Furthermore, this type of rule could raise problems when there is a change in government, because one party can leave a legacy of deficits that must be offset by its successor.

\section{B. A Rule on Spending}

So far we have limited our attention to rules imposed on the level of the deficit. In this section we contrast the results with those that obtain when a rule is set on the aggregate level of public spending. What is the rationale of a rule on the level of spending, rather than on the deficit? Clearly, a rule on spending would be justified in the presence of an 'excess spending bias', either together with or instead of a deficit bias. Of course, this is not the case in the setup that has been considered so far, and therefore a rule on the deficit will outperform a rule on spending with regard to its impact on the structural part of the budget. The interest in considering a rule on spending in this setting arises from its impact on the margin for the cyclical responsiveness of fiscal policy. A (fixed) rule on the deficit hampers the response of both taxes and spending to an output shock, since the effects of such a shock on taxes and spending go in the same direction (increasing or reducing the deficit). A rule on spending, instead, limits the scope for a response of $G$ to shocks, but leaves the margin open for tax smoothing.

We focus here for simplicity on the case in which the government is myopic, and assume that the rule on spending specifies a maximum amount of public expenditure in the first period, given by $\hat{G}$. As in the case of a budget rule, the government has some scope for creative accounting, but it incurs a cost if there is a deviation of actual spending $G_{1}$ from measured spending $\Gamma$. When an output shock $\varepsilon$ is realized, we assume that actual expenditure is $G_{1}-\delta$ $\varepsilon$, and that desired expenditure $G^{*}$ is modified by $\delta \varepsilon$ as well. However, the amount of spending $\hat{G}$ allowed by the rule does not change with $\varepsilon$. As discussed above, the implicit assumption on the tax front is that revenue increases (falls) by the amount $(1-\delta) \varepsilon$ without altering tax rates. The government then chooses $T_{1}, G_{1} T_{2}, G_{2}$ and $\Gamma$ to minimize

$$
L^{g}=\frac{\alpha}{2}\left(G_{1}-G^{*}\right)^{2}+\frac{1}{2} T_{1}^{2}+I \frac{\gamma}{2}\left(G_{1}-\delta \varepsilon-\Gamma\right)^{2}+\beta\left[\frac{\alpha}{2}\left(G_{2}-G^{*}\right)^{2}+\frac{1}{2} T_{2}^{2}\right]
$$

subject to the budget constraint (10). The indicator function $I_{1}=1$ when $\Gamma>\hat{G}$ and 0 otherwise. We assume again that the realization of the shock does not fully offset the "structural bias". Once again the government will choose to comply, at least de iure, with the rule, so that $\Gamma$ is set equal to $\hat{G}$.

The optimal levels of spending, taxes and deficit are reported in the Appendix. Suppose, for example, that the rule sets the spending ceiling at the level desired by private agents, which is $\hat{G}=\alpha G^{*} /(1+\alpha)$. In this case the actual 'structural' level of spending is given by:

$$
G_{1}^{g}=\frac{\alpha}{1+\alpha} G^{*}\left[1+\frac{(1+\alpha)(1-\beta R)}{(\gamma+\alpha)(1+\alpha)+(1+\alpha+\gamma) \alpha \beta R^{2}}\right]
$$


Actual spending exceeds the rule by an amount that depends positively on the size of the deficit bias and negatively on the degree of transparency in the budget.

\section{Fiscal Rules: A Comparison}

We shall first consider the 'structural' part of the budget and then its 'cyclical' part. To compare the structural budget deficit, we need to make some assumptions on $D^{*}$ and on $\hat{G}$. If $D^{*}$ and $\hat{G}$ are set optimally, a budget rule achieves a more desirable outcome with regard to the structural part of the budget. As in the case of a budget rule, the rule that must be imposed on spending to ensure that its level is the one desired by the public is 'tighter' than the one specified above because of the margin for creative accounting (see Appendix, eq.(24) ). In this setting, however, that rule would not be sufficient to ensure that structural fiscal policy is the one desired by the public, because the deficit bias will imply that the intertemporal distribution of taxes is not optimal: taxes will be too low in period 1 and too high in period 2 (see Appendix, eq. (23)). Clearly, given the assumptions we have made about the nature of the deficit bias, a budget rule dominates a spending rule with regard to structural fiscal policy.

How does a rule on spending compare to a rule on the budget with respect to 'cyclical' fiscal policy? Intuition would suggest that a rule on spending would be superior to a rule on the deficit, because it allows more margin to smooth the effects of shocks (it imposes no constraint on taxation). The problem is, however, more complex. When the economy is hit by a temporary shock that, say, raises government revenue and reduces expenditure, the optimal response of the government is to raise spending and reduce taxes, while still saving some of the windfall for the next period. There are two aspects of the optimal response: an intertemporal aspect (related to smoothing of taxes and spending across time) and an intratemporal aspect (how the overall budget response to the shock should be 'split' between tax and expenditure changes). The first aspect is clearly related to the rate of discount, while the second is related to the relative weight of spending deviations from target with respect to tax distortions (i.e., the parameter $\alpha$ ). Under a budget rule, the intertemporal response to the shock is sub-optimal, because the rule prevents the budget from responding sufficiently to the shock and because the government discounts the future more heavily than private agents (the two effects go in opposite directions, as discussed earlier). However, the intratemporal response is optimal--the deficit bias does not affect the relation between optimal expenditure and optimal revenue decisions (see Appendix, eqs (25)-(26)). Under a spending rule, the intertemporal response is also sub-optimal, albeit less so than under a budget rule because taxes can freely respond to the shock. However, the intratemporal response in the first period is distorted by the spending rule (Appendix, eq. (27)). This implies that the rule which is preferable based on cyclical considerations is a priori ambiguous; the crucial parameter is $\delta$ (the relative impact of the shock on spending).

While a full analytical characterization cannot be obtained in closed form, there is a value of $\delta$ for which a spending rule is unambiguously superior (a shock that causes spending to rise/fall exactly by the amount of the 'offset' that the government would choose). More 
generally, when $\delta$ is low, a spending rule tends to be superior to a budget rule from a cyclical perspective (see Figure 1). When $\delta$ is high, results depend on parameter values (if $\alpha$ is low, a spending rule is better). ${ }^{16}$ In general, which rule is preferable will depend on the relative weight of 'structural' and 'cyclical' factors.

The results presented in this section clearly depend on the assumptions underlying the simple model. However, they highlight the importance of carefully examining the interaction between rules, margin for stabilization and underlying fiscal policy biases.

\section{CONCLUDING REMARKS}

This paper has studied the effects of fiscal rules when the government has a margin for 'creative accounting'. In addition to the trade-off between deficit bias and margin for cyclical stabilization, it has emphasized the existence of a second trade-off between (costly) windowdressing and real fiscal adjustment, relating it to the degree of transparency of the budget. Ceteris paribus, a rule imposed when the budget is not transparent yields more creative accounting and less fiscal adjustment. For a given level of budget transparency, the chosen rule will be tighter the higher the probability that the government is fiscally profligate. The existence of a margin for creative accounting also implies that the budget retains some ability to respond to cyclical shocks even in the presence of a numerical budget rule. It was shown that the effects of increased transparency on the cyclical response of the budget to shocks are ambiguous, as emphasized in Proposition 3. Also, a spending rule is not necessarily superior to a budget rule even from a cyclical perspective, even though it does not constrain the response of taxation to shocks.

The model provides reasonable implications of the effects of rules on fiscal policy decisions, as well as a rationale for the imposition of tighter rules (a stricter interpretation of rules) on countries that have a history of fiscal profligacy and less transparent budgets. It has, however, clear limitations. For example, it would be interesting to explore the incentives for creative accounting over longer horizons, allowing for some accumulation of nonrecorded liabilities over time. The model could also be enriched by endogenizing transparency and by a more realistic information structure. In the current setting, a myopic government's choice of creative accounting is merely dictated by the cost of violating the rule, with signaling playing no role. In a more complex setting, in which the government is up for re-election and government preferences matter in the second period as well, a 'good' government would have an incentive to signal its type (as, for example, in Rogoff (1990)). Unlike in that paper, however, here the signaling would imply a larger surplus.

${ }^{16}$ Quantitative details of the welfare analysis are available from the author. 
Figure 1. Fiscal RULES AND "CYClical" LOSSES

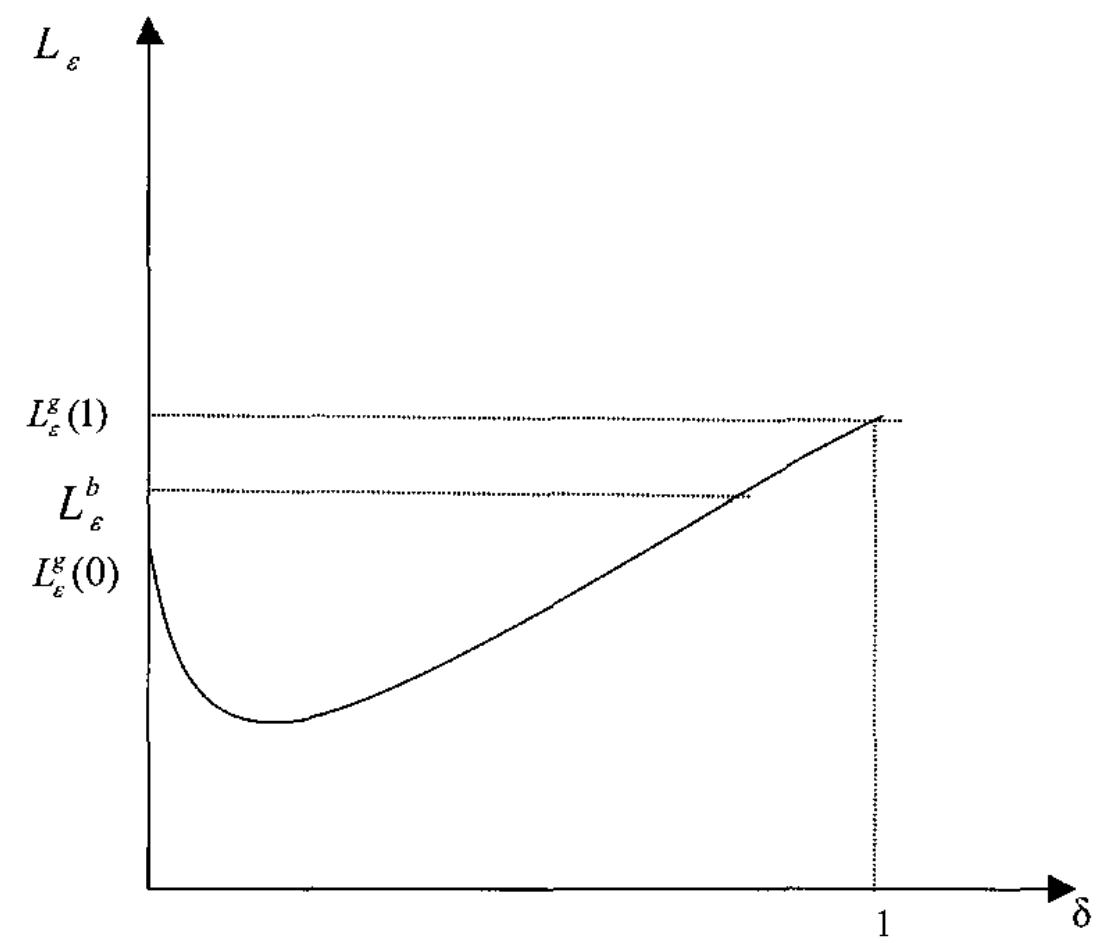

$L_{\varepsilon}^{g}(\delta)=$ Cyclical losses under a spending rule $L_{\varepsilon}^{b}(\delta)=$ Cyclical losses under a budget rule 


\section{Proofs}

A1. Proof of Proposition 2a. The optimal tax and expenditure policy from the point of view of a myopic government under a budget rule $D^{*}$ is given by:

$$
\begin{aligned}
G_{1}^{m r} & =\frac{\alpha}{1+\alpha} G^{*}\left[1+\frac{1-\beta R}{\alpha\left(1+\beta R^{2}\right)+\gamma(1+\alpha)}\right]+\frac{\gamma}{\alpha\left(1+\beta R^{2}\right)+\gamma(1+\alpha)} D^{*} \\
T_{1}^{m r} & =\frac{\alpha}{1+\alpha} G^{*}\left[1-\frac{\alpha(1-\beta R)}{\alpha\left(1+\beta R^{2}\right)+\gamma(1+\alpha)}\right]-\frac{\alpha \gamma}{\alpha\left(1+\beta R^{2}\right)+\gamma(1+\alpha)} D^{*} \\
G_{2}^{m r} & =\frac{\alpha}{1+\alpha} G^{*}\left[1-\frac{R(1-\beta R)}{\alpha\left(1+\beta R^{2}\right)+\gamma(1+\alpha)}\right]-\frac{\gamma R}{\alpha\left(1+\beta R^{2}\right)+\gamma(1+\alpha)} D^{*} \\
T_{2}^{m r} & =\frac{\alpha}{1+\alpha} G^{*}\left[1+\frac{\alpha R(1-\beta R)}{\alpha\left(1+\beta R^{2}\right)+\gamma(1+\alpha)}\right]+\frac{\alpha \gamma R}{\alpha\left(1+\beta R^{2}\right)+\gamma(1+\alpha)} D^{*}
\end{aligned}
$$

For a social planner, the optimal policy in response to a rule $D^{*}<0$ (i.e., requiring a surplus) is given by

$$
\begin{aligned}
& G_{1}^{p r}=\frac{\alpha}{1+\alpha} G^{*}+\frac{\gamma}{\alpha(1+R)+\gamma(1+\alpha)} D^{*} \\
& T_{1}^{p r}=\frac{\alpha}{1+\alpha} G^{*}-\frac{\alpha \gamma}{\alpha(1+R)+\gamma(1+\alpha)} D^{*} \\
& G_{2}^{p r}=\frac{\alpha}{1+\alpha} G^{*}-\frac{\gamma R}{\alpha(1+R)+\gamma(1+\alpha)} D^{*} \\
& T_{2}^{p r}=\frac{\alpha}{1+\alpha} G^{*}+\frac{\alpha \gamma R}{\alpha(1+R)+\gamma(1+\alpha)} D^{*}
\end{aligned}
$$

The optimal rule is determined as follows. The public chooses $D^{*}$ so as to minimize its loss function

$$
L^{p}=E\left(\frac{\alpha}{2}\left(G_{1}-G^{*}\right)^{2}+\frac{1}{2} T_{1}^{2}+\frac{1}{R}\left[\frac{\alpha}{2}\left(G_{2}-G^{*}\right)^{2}+\frac{1}{2} T_{2}^{2}\right]\right)
$$

subject to $\left(G_{1}, G_{2}, T_{1}, T_{2}\right)$ being chosen optimally by the government (equations (16)-(17)). This yields the following expression:

where

$$
D^{*}=-\frac{\alpha q(1-\beta R) G^{*}}{\gamma(1+\alpha)\left[q+(1-q) C_{1}^{2}\right]}
$$

$$
C_{1}=\frac{\alpha\left(1+\beta R^{2}\right)+\gamma(1+\alpha)}{\alpha(1+R)+\gamma(1+\alpha)}<1
$$

Using (16) and (17), we can find the rule $D_{b b}^{*}$ that ensures, in expected value terms, a balanced budget: 


$$
D_{b b}^{*}=-\frac{\alpha q(1-\beta R) G^{*}}{\gamma(1+\alpha)\left[q+(1-q) C_{1}\right]}
$$

It is straightforward to see that the surplus implied by (19) is larger than the one implied by (21). Note also that $D^{*}$ is decreasing in $q$ (a higher $q$ implies a larger surplus).

A2. Proof of Proposition 2b. The optimal rule $D_{2 b}^{*}$ is the level of $D^{*}$ that minimizes (9), subject to $\left(G_{1}, G_{2}, T_{1}, T_{2}\right)$ being chosen optimally by the government. This yields the following expression:

$$
D_{2 b}^{*}=-\frac{\alpha q(1-\beta R)\left[1+R-m\left(1+\beta R^{2}\right)\right] G^{*}}{\gamma(1+\alpha)(1+R)\left[q+(1-q) C_{1}^{2}\right]+\alpha m\left(1+\beta R^{2}\right)^{2}\left[q+(1-q)\left(C_{1} \frac{1+R}{1+\beta R^{2}}\right)^{2}\right]}
$$

The rule entails a budget surplus as long as $m<(1+R) /\left(1+m \beta R^{2}\right)$, proving Proposition $2 \mathrm{~b}$. As $m$ increases, the required surplus falls. Plugging this expression into the one for the expected budget balance (obtained using (16) and (17)), it is straightforward to prove that for $m=1$ the rule implies an expected budget deficit.

A3. Spending rule (structural part). The optimal 'structural' level of taxes and expenditures under a spending rule $s$ for a myopic government $m$ is given by:

$$
\begin{gathered}
G_{1}^{m s}=\frac{\alpha G^{*}\left[1-\beta R+\alpha\left(1+\beta R^{2}\right)\right]+\gamma \hat{G}\left[1+\alpha\left(1+\beta R^{2}\right)\right]}{(1+\alpha+\gamma) \alpha \beta R^{2}+(1+\alpha)(\alpha+\gamma)} \\
T_{1}^{m s}=\alpha \beta R \frac{[\alpha(1+R)+\gamma] G^{*}+\gamma R \hat{G}}{(1+\alpha+\gamma) \alpha \beta R^{2}+(1+\alpha)(\alpha+\gamma)} \\
G_{2}^{m s}=\frac{\alpha G^{*}\left[\left(1+\beta R^{2}\right)(\alpha+\gamma)-R(1-\beta R)\right]-\gamma R \hat{G}}{(1+\alpha+\gamma) \alpha \beta R^{2}+(1+\alpha)(\alpha+\gamma)} \\
T_{2}^{m s}=(\beta R)^{-1} T_{1}^{m s}
\end{gathered}
$$

The spending rule that maximizes agents' welfare takes the form

$$
\hat{G}^{p s}=\frac{\alpha \gamma\left(1+\beta R^{2}\right)\left[1+\alpha\left(1+\beta R^{2}\right)\right]-\alpha R(1-\beta R)^{2}}{(1+\alpha) \gamma\left(1+\beta R^{2}\right)\left[1+\alpha\left(1+\beta R^{2}\right)\right]+\gamma R(1-\beta R)} G^{*}
$$

This rule sets spending below the level desired by agents in period 1, which is $\alpha G^{*} /(1+\alpha)$, because the government will do some creative accounting.

A4. Budget rule (cyclical response). The public's desired response to shocks is given by:

$$
\begin{aligned}
G_{1 \varepsilon}^{p} & =G_{2 \varepsilon}^{p}=\frac{1}{1+\alpha} \frac{R}{1+R} \varepsilon \\
T_{1 \varepsilon}^{p} & =T_{2 \varepsilon}^{p}=-\frac{\alpha}{1+\alpha} \frac{R}{1+R} \varepsilon
\end{aligned}
$$


so that there is perfect 'smoothing' of the shock. The optimal government response is instead

$$
\begin{gathered}
G_{1 \varepsilon}^{m r}=\frac{\alpha \beta R^{2}+\gamma(1+\alpha)}{(1+\alpha)\left[\alpha\left(1+\beta R^{2}\right)+\gamma(1+\alpha)\right]} \varepsilon \\
T_{1 \varepsilon}^{b}=-\alpha G_{1 \varepsilon}^{b} \\
G_{2 \varepsilon}^{m r}=\frac{\alpha R}{\alpha \beta R^{2}+\gamma(1+\alpha)} G_{1 \varepsilon}^{m r} \\
T_{2 \varepsilon}^{m r}=-\alpha G_{2 \varepsilon}^{m r}
\end{gathered}
$$

where the superscript $r$ indicates a budget rule.

A5. Spending rule (cyclical response). The optimal government response to shocks in the presence of a rule on spending is given by:

$$
\begin{gathered}
G_{1 \varepsilon}^{m s}=\frac{\alpha \beta R^{2}+\gamma \delta\left[1+\alpha\left(1+\beta R^{2}\right)\right]}{(1+\alpha+\gamma) \alpha \beta R^{2}+(1+\alpha)(\alpha+\gamma)} \varepsilon \\
T_{l_{\varepsilon}}^{m s}=-\frac{\alpha \beta R^{2}[\alpha+\gamma(1-\delta)]}{(1+\alpha+\gamma) \alpha \beta R^{2}+(1+\alpha)(\alpha+\gamma)} \varepsilon \\
G_{2 \varepsilon}^{m s}=-(\alpha \beta R)^{-1} T_{1 \varepsilon}^{m s} \\
T_{2 \varepsilon}^{m s}=(\beta R)^{-1} T_{1 \varepsilon}^{m s}
\end{gathered}
$$

The welfare analysis of Section III.3 is conducted by plugging (17) and (26) for the deficit rule and (23) and (27) for the spending rule in private agents' loss function. 


\section{REFERENCES}

ACIR (Advisory Commission on Intergovernmental Relations) (1987), "Fiscal Discipline in a Federal System," ACIR: Washington D.C.

Alesina, Alberto and Alex Cukierman (1990), "The Politics of Ambiguity," Quarterly Journal of Economics 105, 829-50.

Alesina, Alberto, Ricardo Hausmann, Rudolf Hommes and Ernesto Stein (1996), "Budget Institutions and Fiscal Performance in Latin America," NBER Working Paper 5586, May.

Alesina, Alberto and Roberto Perotti (1995), "The Political Economy of Budget Deficits," IMF Staff Papers 42, March, 1-31.

Alesina, Alberto and Guido Tabellini (1990), "A Positive Theory of Fiscal Deficits and Government Debt," Review of Economic Studies 57, July, 403-14.

Auerbach, Alan and Lawrence Kotlikoff (1987), Dynamic Fiscal Policy, Cambridge: Cambridge University Press.

Bayoumi, Tamim and Barry Eichengreen (1995), "Restraining Yourself: The Implications of Fiscal Rules for Economic Stabilization", IMF Staff Papers 42, March, 32-48.

Beetsma, Roel M. W. J. and Harald Uhlig (1999), "An Analysis of the Stability Pact," Economic Journal 109, October, 546-71.

Blejer, Mario I. and Adrienne Cheasty (1991), "The Measurement of Fiscal Deficits: Analytical and Methodological Issues," Journal of Economic Literature 29, December, 1644-78.

Bohn, Henning (1992), "Budget Deficits and Government Accounting," Carnegie-Rochester Conference Series on Public Policy 37, December, 1-84.

Bohn, Henning and Robert P. Inman (1996), "Balanced Budget Rules and Public Deficits:

Evidence from the US States," Carnegie-Rochester Conference Series on Public Policy 45, December, 13-76.

Buiter, Willem, Giancarlo Corsetti and Nouriel Roubini (1993), "Excessive Deficits: Sense and Nonsense in the Treaty of Maastricht," Economic Policy 17, April, 58-100.

Bunch, Beverly S. (1991), "The Effect of Constitutional Debt Limits on State Governments' use of Public Authorities," Public Choice 68, January, 57-69. 
Chari, V. V. and Patrick J. Kehoe (1997), "On the Need for Fiscal Constraints in a Monetary Union," Federal Reserve Bank of Minneapolis, September.

Corsetti, Giancarlo and Nouriel Roubini (1997), "Politically Motivated Fiscal Deficits: Policy Issues in Closed and Open Economies," Economics and Politics 9, March, 27-54.

Dur, Robert A. J., Ben D. Peletier, and Otto H. Swank (1997), "The Effects of Fiscal Rules on Public Investment if Budget Deficits Are Politically Motivated," mimeo, November.

Easterly, William (1999), "When is Fiscal Adjustment an Illusion?," Economic Policy 28, April, 57-76.

Kiewiet, D. Roderick and Kristin Szakaly (1996), "Constitutional Limitations on Borrowing: Analysis of State Bonded Indebtedness," Journal of Economics, Law and Organization, April, 62-97.

Kopits, George and Jon Craig (1998), "Transparency in Government Operations," IMF Occasional Paper 158, February.

Kopits, George and Steven Symansky (1998), "Fiscal Policy Rules," IMF Occasional Paper 162.

Obstfeld, Maurice (1997), "Destabilizing Effects of Exchange-Rate Escape Clauses," Journal of International Economics 43, August, 61-77.

Poterba, James M. (1994), "State Responses to Fiscal Crises: The Effects of Budgetary Institutions and Politics," Journal of Political Economy 102, August, 799-821. (1995), "Balanced Budget Rules and Fiscal Policy: Evidence from the States," National Tax Journal XLVIII No. 3, 329-36.

Rogoff, Kenneth (1990), "Equilibrium Political Budget Cycles," American Economic Review 80, March, 21-36.

Rogoff, Kenneth and Anne Sibert (1988), "Elections and Macroeconomic Policy Cycles," Review of Economic Studies 55, January, 1-16.

Schmitt-Grohé, Stephanie, and Martín Uribe (1997), "Balanced-Budget Rules, Distortionary Taxes, and Aggregate Instability," Journal of Political Economy 106, October, 9761000 .

Tornell, Aaron and Philip Lane (1998), "Are Windfalls a Curse? A Non-Representative Agent Model of the Current Account," Journal of International Economics 44, February, 83-112. 
von Hagen, Jürgen (1991), "A Note on the Empirical Effectiveness of Formal Fiscal Restraints," Journal of Public Economics 44, March, 199-210.

von Hagen, Jürgen and Ian Harden (1994), "National Budget Processes and Fiscal Performance," European Economy, Reports and Studies No. 3, 311-418.

(1996), "Budget Processes and Commitment to Fiscal Discipline," IMF Working Paper 96/78. July. 